\title{
On the optimisation of a direct current (dc) hot- wall refrigerator
}

\author{
Ciro Aprea ${ }^{1}$ and Angelo Maiorino, ${ }^{1, *}$ \\ ${ }^{1}$ Department of Industrial Engineering, University of Salerno, Via Giovanni Paolo II, $132-84084$ \\ Fisciano (SA), Italy
}

\begin{abstract}
This study presents an experimental investigation conducted on a refrigerator powered by direct current and composed of a $166 \mathrm{~L}$ cabinet, a condenser embedded in the external wall of the compartment (hot-wall), an internal static evaporator, a hermetic variable speed compressor. The refrigerant fluid used is the R290a, a natural fluid. By placing the refrigerator in a temperature-controlled environment, four external temperatures have experimented: $22,25,29$ and $32{ }^{\circ} \mathrm{C}$. Three different temperature setpoints have been set for each temperature: $-5,-10,-20{ }^{\circ} \mathrm{C}$. In this way, 12 test conditions were defined, and each of them was repeated by imposing four different compressor rotation speeds: 2000, 2500, 3000, $3500 \mathrm{rpm}$. The set of tests allowed to identify for each operating condition the optimal number of operating revolutions aimed at minimising the energy consumption of the analysed device.
\end{abstract}

\section{Introduction}

Improvements and reduction in the energy consumption of refrigerator compressors are fundamental for the refrigeration industry. Domestic, pharmaceutical and clinical refrigeration systems have the chance to be powered through green applied sciences such as photo voltaic energy. Green technologies have been focusing on both lowering electricity usage or growing environmentally friendly systems worldwide. In the case of vapour compressor refrigeration (VC), there are two distinct alternatives for powering the compressor, which is choice present day (AC) or direct current (DC). A compressor is mixture of a mechanical compression part and an electrical motor. An electrical motor converts electrical energy to mechanical energy in a refrigeration compressor. An AC current compressor is powered by alternative voltage such as one hundred twenty or $220 \mathrm{~V}$ and 50 $\mathrm{Hz}$. Electrical motor of the AC compressor is an AC induction type.

On the different hand, DC compressor requires low voltage and direct current supply such as 12-24 V. Even though, DC compressor has comparable mechanical compression part with AC compressor, it has a brushless electric motor. Green energy technologies can be used to feed a DC compressor directly whilst an AC compressor requires a power inverter. Energy utilization reduction via increased efficiency and use of renewable energy employing DC compressors is a benefit of such systems. There are different uses of small-sized refrigeration systems besides household use. Many vehicles such as trucks, caravans, boats, cars, etc. are

\footnotetext{
*Corresponding author: amaiorino@unisa.it
} 
frequently outfitted with transportable cooling appliances. Modulation techniques are used to enhance compressor and refrigeration device efficiency. As mentioned by [1] the speed modulation can make contributions to improving the coupling between the photo voltaic energy source and the refrigeration duty for a domestic refrigerator. Variable speed operation is positive in that aspect as it gives lower compressor surface temperature, lower discharge temperatures, and a higher COP [2]. To optimise the working of a VCDC refrigerator thanks to the speed modulation, a controller has to drive the compressor via changing the voltage input to the DC motor. The optimal operating conditions could be carried out thanks to a refrigerator map provided by an experimental characterisation of the set cabinet-refrigeration circuit. Even if the literature [1-4] offers a lot of experimental works each on the optimal control and on the methodology to characterise a VCDC refrigerator, there is a gap in performance evaluation of VCDC refrigerators using a hot-wall condenser. Currently, hotwall condensers are being extensively used round the world, especially in the Asian market, mostly due to aesthetic and value reasons. In this kind of heat exchanger, the condenser tubes are connected to the internal surface of the refrigerator outer metal sheet with the aid of an adhesive tape, so that the exterior walls act like fins and enhance the heat transfer to the ambient. As pointed out in [5], a hot-wall condenser influences the thermal load over the refrigerated compartments, and then it can have an effect on the behaviour of the cabinetrefrigeration circuit set. To shut this gap, right here an experimental evaluation is introduced for a hot-wall VCDC (HWVCDC) refrigerator, and its mapping is carried out.

\section{Experimental apparatus}

\subsection{Refrigeration system}

Experiments have been carried out on a $166 \mathrm{~L}$ refrigerator employing a DC type compressor working with the natural refrigerant R290a. A set of thermoresistances allowed to measure air temperatures inside the cabinet and surrounding it, while an energy meter carried out the energy and power input for the compressor. In the experimental setup, a SECOP BD80CN DC compressor was used. This compressor is a reciprocating type. It is suitable for use in mobile applications such as cooling boxes, boats, caravans, trucks, vans and buses, and is also suitable for stationary applications powered by solar energy. A programmable DC power supply was adopted to guarantee the right feeding to the compressor (10 A as maximum current and $12 \mathrm{~V}$ as maximum voltage), while a potentiometer has been connected to the driver of the compressor. The electrical resistance of the potentiometer was included in the range 191-1674 $\Omega$ to which corresponded the speed range 2044-3495 rpm. The manufacturer has provided the relation between the electrical resistance $\left(\mathrm{R}_{\mathrm{rm}}\right)$ and the speed of the compressor (rpm):

$$
R_{r p m}=-5.68 * 10^{4} \mathrm{rpm}^{2}+2.04 \mathrm{rpm}+1.67 * 10^{3}
$$

The cabinet is made by a sandwich of thermal insulation panels including in the outer side a static condenser and in the inner side a static evaporator. Using a heat flux meter, the overall thermal transmittance of the walls was measured, and it resulted equal to $0.254 \mathrm{~W} / \mathrm{m}^{2} \mathrm{~K}$.

To select different setpoint for the cabinet temperature and to select the desired hysteresis band, the electronic thermostat set up by the manufacturer of the cabinet was bypassed. Then, a virtual instrument (implemented in Labview) which received as an input the air temperature inside the cabinet, took control of the programmable DC power supply. 


\subsection{Climatic testing room}

All the tests were carried out by keeping the refrigerator inside a $27 \mathrm{~m}^{3}$ climatic testing room. A set of electric heaters warmed the air surrounding the cabinet, while a humidifier vaporised water in the air. A control unit made in house and based on Arduino was adopted to control both the humidity and the air temperature surrounding the cabinet. During all the tests, the average temperature and the humidity inside the climatic testing room were close to the desired value $\left( \pm 1.3^{\circ} \mathrm{C}\right.$ and $\left.\pm 8 \%\right)$. The room air temperature standard deviations varied from 0.6 and $2.0^{\circ} \mathrm{C}$.

\section{Experimental work}

\subsection{Test procedure}

A simplified methodology inspired to IEC 62552 [6] has been considered to design a set of experiments aimed at the measurement of the energy consumptions for different setpoint temperatures, external air temperatures and compressor speeds. Then, four external temperatures have experimented: $22,25,29$ and $32{ }^{\circ} \mathrm{C}$; three different temperature setpoints have been set for each temperature: $-5,-10,-20^{\circ} \mathrm{C}$. In this manner, 12 test conditions were defined, and each of them was repeated by imposing four different compressor speeds: 2000 , $2500,3000,3500 \mathrm{rpm}$. Each of the 48 tests lasted $24 \mathrm{~h}$, and each of them was repeated at least thrice to reduce the accidental errors. A data logger connected to a personal computer allowed to record the temperature values and the power absorbed by the compressor. A virtual instrument implemented in Labview managed all the data and allowed to carry out all indirect measurements necessary to the experimental analysis, which is reported below.

\subsection{Analysis}

Downstream of the 48 tests, a set of indirect measures have been calculated, such as:

- the duty cycle

$$
\delta=t_{o n} /\left(t_{o n}+t_{o f f}\right)
$$

- the number of daily cycles

$$
n_{\text {day }}=24 \mathrm{~h} /\left(t_{\text {on }}+t_{\text {off }}\right)
$$

- the i-th absorbed energy during a turn-on state

$$
E_{e l, i}=\int_{t_{i}}^{t_{f}} P_{e l}(t) d t
$$

where $t_{i}$ is the instant at which the compressor turned on, while at $t_{f}$ it the turned off;

- $\quad$ the 24-h absorbed electrical energy

$$
E=\sum_{i=1}^{n, d a y} E_{e l, i}
$$




\section{Results and comments}

Looking at the IEC 62552 [6] the test at $25^{\circ} \mathrm{C}$ and $32^{\circ} \mathrm{C}$ play a role of interest in the definition of the energy labels for a refrigerator. As a consequence of that and with the aim to summary the experimental results, Fig.1 and Fig.2 respectively report the $\delta$ and the E values for the above-mentioned temperature levels. At any external air temperature and for a constant setpoint temperature, an increase of the compressor speed leads to a reduction of the duty cycle (Fig.1). That was to be expected: with high probability, the rise of the rotational speed allows to the compressor to provide a higher mass flow rate of refrigerant for the evaporation; then, the refrigerator develop a higher refrigeration duty; also, because both the external air temperature and the thermal load is kept constant, the $t_{\mathrm{on}}$ drops, while the $\mathrm{t}_{\mathrm{of}}$ doesn't change. At any external air temperature and for the same compressor speed, a lower setpoint temperature leads to a higher duty cycle. That is primarily due to the higher temperature difference between the external air temperature and the inner air temperature, that causes a higher thermal load through the walls and a higher compression ratio. The latter produces a reduction of the mass flow rate of refrigerant; then, whereas the change of available latent heat at the evaporator is neglectable, the refrigeration duty decreases. Both considerations bring to justify a reduction of the duty cycle, because contemporarily the $t_{\mathrm{m}}$ increases and the $\mathrm{t}_{\text {orf }}$ decreases.
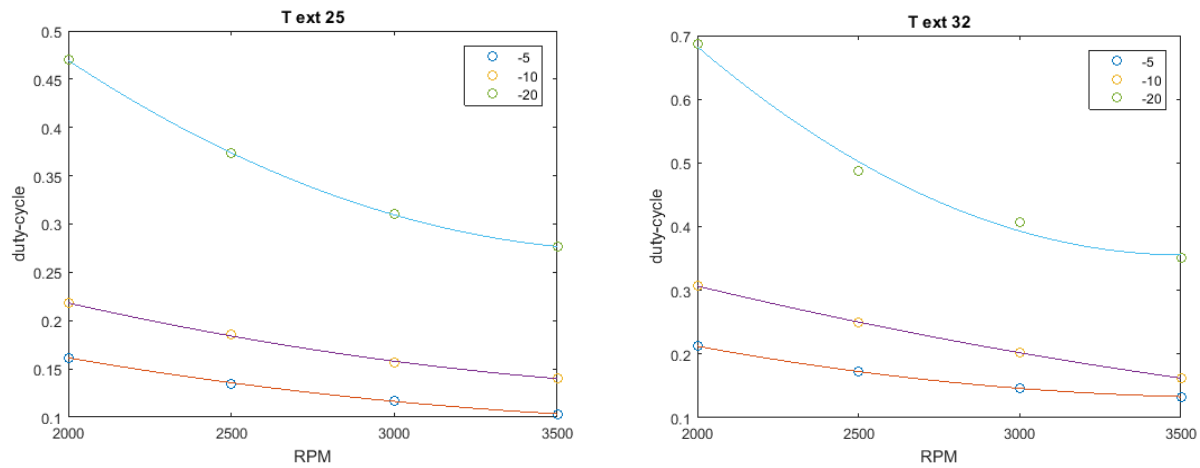

Fig. 1. Duty cycle versus compressor speed at external air temperature equal to $25^{\circ} \mathrm{C}$ and to $32^{\circ} \mathrm{C}$ and for setpoint temperature equal to $-5^{\circ} \mathrm{C},-10^{\circ} \mathrm{C}$ and $-20^{\circ} \mathrm{C}$.

At any external air temperature, Fig.2 reveals the existence of an optimal compressor speed for each setpoint temperature. At the optimal rotational speed, the compressor guarantees the best COP, where the latter is meant as the ratio between the thermal energy sought at the evaporator and the 24-h absorbed electrical energy.

By neglecting the fluctuation of the duty cycle at $\mathrm{Text}=32^{\circ} \mathrm{C}$ and setpoint temperature =$10^{\circ} \mathrm{C}$, the optimal operating condition move to high rotational speeds for low setpoint temperatures. 

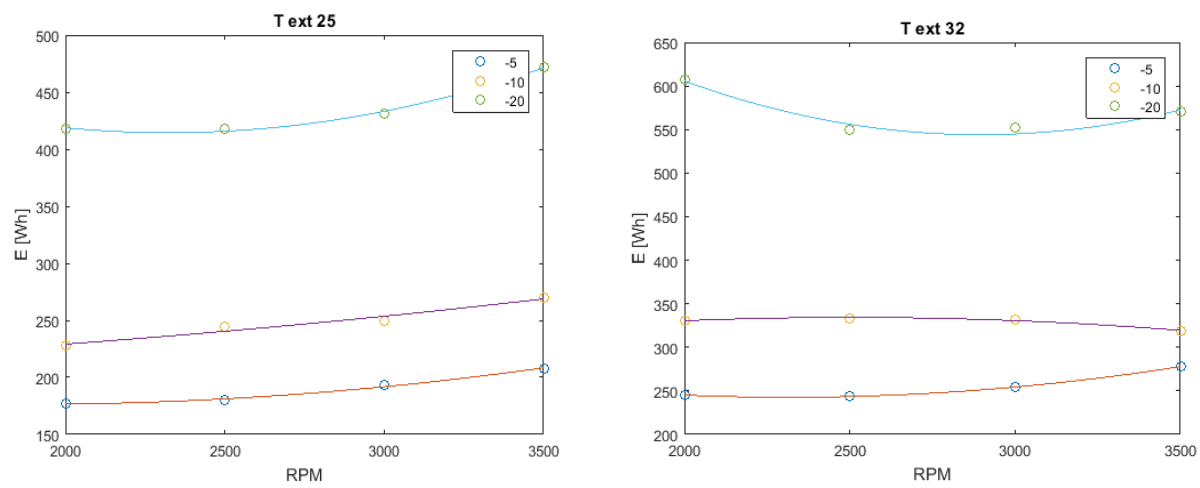

Fig. 2. 24-h absorbed electrical energy versus compressor speed at external air temperature equal to $25^{\circ} \mathrm{C}$ and to $32^{\circ} \mathrm{C}$ and for setpoint temperature equal to $-5^{\circ} \mathrm{C},-10^{\circ} \mathrm{C}$ and $-20^{\circ} \mathrm{C}$.

\section{Optimisation}

All the experimental results have been collected and employed to achieve an empirical model of the analysed HWDCVC. The model has been designed to represent for each setpoint temperature the functional link among the 24-h absorbed electrical, the external air temperature and the compressor speed.

$$
E=f\left(r p m, T_{\text {ext }}\right)
$$

The easiest and very efficient way to carry out the model described in the Eq.6 was the definition of the following polynomial regression:

$$
E=c_{1}+c_{2} r p m+c_{3} r p m^{2}+c_{4} T_{\text {ext }}+c_{5} T_{\text {ext }}^{2}+c_{6} r p m T_{\text {ext }}
$$

of which the coefficient $\mathrm{c}_{\mathrm{i}}$ (Tab. 1) provides a coefficient of determination $\left(\mathrm{R}^{2}\right)$ included in the range 0.94-0.98.

Table 1. $c_{i}$ values.

\begin{tabular}{|l|c|c|c|c|c|c|}
\hline & $c_{1}$ & $c_{2}$ & $c_{3}$ & $c_{4}$ & $c_{5}$ & $c_{6}$ \\
\hline$-5^{\circ} \mathrm{C}$ & 574,86 & $-5,79$ & 0,18 & $-0,55$ & $-337,46$ & 80,36 \\
\hline$-10^{\circ} \mathrm{C}$ & 138,91 & 7,18 & 0,04 & $-2,80$ & $-113,22$ & 55,36 \\
\hline$-20^{\circ} \mathrm{C}$ & 799,25 & $-14,19$ & 0,59 & $-6,33$ & $-302,08$ & 119,05 \\
\hline
\end{tabular}

The graphical representation of the empirical model is reported in Fig. 3. Because the Eq.7 represents a continuous function, it is easy to find the optimal operating conditions by solving the following minimisation problem:

$$
\min (E)=f\left(r p m, T_{\text {ext }}\right)
$$

For an actual situation, the only degree of freedom in the Eq.8 is the compressor speed, because the external air temperature depends on heterogeneous factors. 

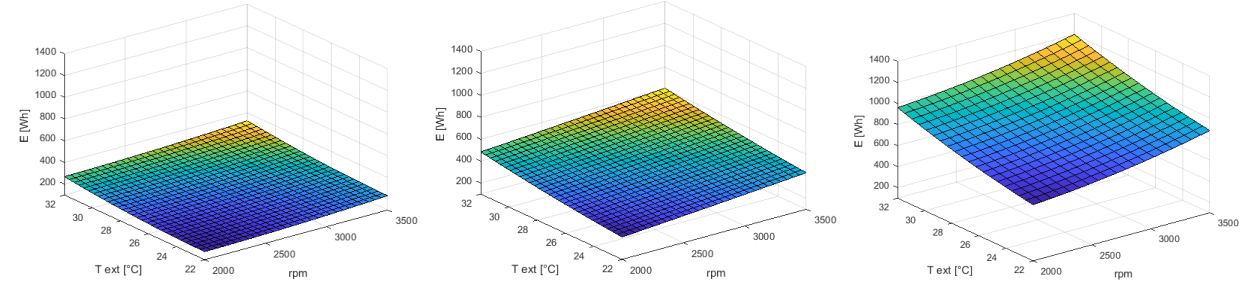

Fig. 3. 24-h absorbed electrical energy versus compressor speed and external air temperature for setpoint temperatures equal to $-5,-10$ and $-20^{\circ} \mathrm{C}$ (by the left to right).

To build an easy control system, one can consider implementing an electronic board connected to a thermal sensor to measure the external air temperature and to a potentiometer. As the first step, the controller could find the optimal compressor speed thanks to Eq. 7 and 8. Then, considering the Eq. 1, the controller could send a signal to a servo-commanded potentiometer to set the right electrical resistance to modulate the rotational speed of the compressor.

\section{Conclusions}

In this paper, an experimental analysis to detect the characteristic map of a 166L HWDCVC refrigerator has been reported. A set of 48 experiments, inspired to the IEC 62552 [6], allowed to achieve an exhaustive knowledge on the behaviour of the refrigerator in terms of duty cycle and 24-h absorbed electrical energy. The experimentation reveals the existence of an optimal compressor speed for each setpoint temperature. Also, the optimal operating condition moves to high rotational speeds for low setpoint temperatures. Thanks to the collected data, a continuous function has been carried out to detect the link among the 24-h absorbed electrical, the external air temperature and the compressor speed. The function provides an accurate empirical model which can be used as basis for a controller designed to reduce the 24-h absorbed electrical energy.

\section{References}

1. P. Su, J. Ji, J. Cai, Y. Gao, K. Han, , Renew. Energy. 152, 155-164 (2020).

2. O. Ekren, S. Celik, B. Noble, R. Krauss, Int. J. Refrig. 36, 745-757 (2013).

3. A.A.M. El-Bahloul, A.H.H. Ali, S. Ookawara, , Energy Procedia. 70, 634-643 (2015).

4. J. Tsado, M.K. Mahmood, A.G. Raji, A.U. Usman, I.N. Jiya, 2018 IEEE PES/IAS PowerAfrica, PowerAfrica 2018, 2018.

5. C. Espíndola, Rodolfo da Silva; Knabben, Fernando Testoni; Melo, Int. Refrig. Air Cond. Conf., p. Paper 1847 (2018).

6. IEC, 62552-1:2015, 2015. 